\title{
Vrednotenje vplivov EU na področju mladinske politike na subnacionalni in nacionalni ravni: primer programa Mladi v akciji v Sloveniji ${ }^{1}$
}

UDK: 323:316.346.32053.6(045)

\author{
Mateja Cugmas \\ Univerza v Ljubljani, Fakulteta za družbene vede \\ mateja.cugmas@gmail.com \\ Simona Kustec Lipicer \\ Univerza v Ljubljani, Fakulteta za družbene vede \\ simona.kustec-lipicer@fdv.uni-lj.si
}

\section{IZVLEČEK}

V članku se osredotočamo na analizo dosedanjih vplivov programa EU Mladi v akciji (2007-2013) na nacionalnih in subnacionalnih ravneh mladinske politike v Sloveniji. Program je zastavljen z namenom povečanja zavzetosti mladih in krepitve ključnih kompetenc za vseživljenjsko učenje, kar naj bi povečevalo zaposljivost in vključevanje mladih $v$ družbo. $Z$ analizo izvajanja programa poskušamo $z$ vidika vsebine zastavljenih ciljev, upravljavskih vidikov in ocene učinkov ciljev ovrednotiti, kako se v doseženih rezultatih izvajanja programa odraža koncept večnivojskosti in ali ima izbrana javna politika pričakovane učinke na mlade. Za konkretno študijo vzamemo primer podravske regije, ki je na polju mladinske politike označena kot najmanj razvita. Raziskovalne ugotovitve kažejo, da so učinki ciljev programa MvA na mlade v izbrani regiji prevladujoče uspešni, a se hkrati kot pomembna in pomanjkljiva kaže odsotnost klasičnega večnivojskega upravljanja samega programa in nadalje tudi mladinske politike $v$ širšem smislu.

Ključne besede: večnivojsko upravljanje, vrednotenje, mladinska politika, program Mladi v akciji 2007-2013, Podravje

JEL: Z18

1 Izhodišče za pripravo članka predstavljajo spoznanja diplomskega dela Vrednotenje evropskega sodelovanja na področju mladinske politike v Sloveniji (Cugmas, 2011). Avtorici tega članka sta za omenjeno diplomsko delo prejeli priznanje Mladinskega sveta Slovenije za najboljše diplomsko delo in mentorstvo.

Cugmas, M. \& Kustec Lipicer, S. (2012). Vrednotenje vplivov EU na področju mladinske politike na subnacionalni in nacionalni ravni: primer programa Mladi v akciji v Sloveniji. Uprava/Administration X(3), 97-108. 


\section{Uvod}

Vodilno načelo mladinske politike je utemeljeno na spodbujanju in ponujanju pozitivnih materialnih in nematerialnih transferjev, ki pripomorejo $k$ izboljšanju in razvijanju življenjskih razmer mladih in k njihovi vsesplošno večji participativnosti v družbi. Mladinska politika ima naravo povezovalne, medsektorske politike, katere namen je sodelovanje mladih z upoštevanjem celotnega obsega družbenih, kulturnih in političnih vsebin, ki zadevajo mlade (European Union, 2012). V okviru opisanega izjemno pomembno vlogo prevzema mladinsko delo, ki je oblika dela z mladimi in poteka prostovoljno. Pri tem morajo mladi najti motivacijo za participacijo in zadovoljitev aktualnih potreb ter pridobiti znanja in spretnosti, ki jih potrebujejo v vaakdanjem življenju, a jih ne pridobijo v drugih formalnih sistemih (Kuhar, Leskovšek, 2008, str. 328). Poleg izobraževanja, ki velja za tipično mladinsko vertikalo, izvajanje dela z mladimi obsega tudi ukvarjanje s temami kot so zaposlovanje, stanovanjska politika, družinska in demografska politika, mladi z manj priložnostmi, medgeneracijska solidarnost in sožitje (Cepin, 2009, str. 8).

$\checkmark$ tem članku je osrednji poudarek namenjen evalvacijski analizi slovenske izkušnje z izvajanjem in upravljanjem programa Mladi v akciji 2007-2013 (v nadaljevanju MvA) ter učinkom, ki ga le-ta prinaša na različnih političnih ravneh, na katerih deluje - lokalni, nacionalni in nadnacionalni, ter za različne skupine mladih, kot neposrednih uporabnikov tega programa. $V$ okviru izvajanja aktualnega programa MvA morajo na lokalni ravni prijavljeni in izvedeni projekti zasledovati naslednje vsebine: mladinske izmenjave in pobude, izvajanje mladinske demokracije, evropsko prostovoljstvo, sodelovanje mladih s sosednjimi državami Evropske unije, usposabljanje in povezovanje v mrežo tistih, ki so aktivni v mladinskem delu in mladinskih organizacijah in podpiranje evropskega sodelovanja na mladinskem področju (Movit na mladina, 2009). Skozi neposredno izkušnjo z izvajanjem programa v podravski regiji, ki v okviru mladinske politike na nacionalni ravni velja kot najmanj razvita, bomo v tem članku izvedli večnivojsko evalvacijsko študijo z naslednjih vidikov:

- vsebinske skladnosti ciljev;

- upravljavskih vidikov;

- ocene doseženih učinkov.

Empirični del študije temelji na kritični in primerjalni analizi primarnih in sekundarnih virov in na podatkih iz polstrukturiranih intervjujev, ki smo jih med leti 2010 in 2011 izvedli na Uradu za mladino, pri nacionalnih koordinatorjih programa Movit na mladina in na Mladinskem svetu Slovenije. Pomemben vir podatkov črpamo tudi iz raziskovalnih podatkov, ki so bili za Evropsko komisijo zbrani v okviru priprave t. i. vmesne evalvacijske študije izvajanja programa MvA 2007-2010 v Sloveniji (Kustec Lipicer \& Deželan, 2010; Kustec Lipicer \& Deželan, 2010a). 


\section{Mladinska politika in EU}

Mladinska politika na ravni EU je bila prvič pravno opredeljena leta 1993 z Maastrichtsko pogodbo. Danes jo opredeljuje peti odstavek 165(2). člena Pogodbe o delovanju Evropske unije (TFEU), ki določa, da so cilji dejavnosti Unije spodbujanje razvoja izmenjave mladih ter izmenjave pedagoških in drugih strokovnih delavcev ter spodbujanje sodelovanja mladih v demokratičnem življenju v Evropi (Treaty on the Functioning of the European Union, 165(2). Article). Ekonomsko socialni odbor in odbor regij dajeta pomen mladinski politiki predvsem v smislu, da mora ceniti mlade kot družbeni potencial in jim omogočiti, da postanejo dejavni, svobodni in odgovorni (White Paper, 2001).

Strateški politični okviri in cilji javne politike mladinske politike EU so bili sprejeti leta 2001 v Beli knjigi »Nova spodbuda za evropsko mladino« (European Commission, 2012). Bela knjiga je predlagala nov okvir za povečanje sodelovanja med igralci na področju mladinske politike ter večje upoštevanje mladih v odločitvah sektorske politike (White Paper on Youth, 2011). Omenjeni dokument je bil leta 2009 pomembno strateško izdelan z Evropsko strategijo za mlade (European Commision, 2012), ki posveča posebno pozornost mladim z manj priložnostmi. Strategija predstavlja medsektorski politični pristop k mladinskim vprašanjem, ob tem pa krepi sodelovanje pri oblikovanju politik na vseh političnih ravneh.

Drug pomembni dokument je resolucija Sveta EU o prenovljenem okviru za evropsko sodelovanje na področju mladih (European Commision, 2012). Resolucija je bila oblikovana za zagotovitev boljših pogojev evropske mladine. Njen cilj je izboljšati učinkovitost in uspešnost evropskega sodelovanja z vzpostavitvijo strategije za naslednje desetletje, ki gradi na doseženem napredku ter izkušnjah iz prejšnjega okvira. Nova strategija EU za mlade opredeljuje dva splošna cilja novega okvira: več priložnosti in enake možnosti za mlade v izobraževanju in na trgu dela ter dejavno državljanstvo, socialno vključenost in solidarnost mladih (Nogueira, 2012).

Že pred omenjenimi aktivnostmi je bila mladinska politika v EU osredotočena na razpisovanje programov, namenjenih mladinskim organizacijam na nacionalnih in subnacionalnih ravneh, najprej s programom »Mladi za Evropo« iz leta 1988, da bi vzpodbudili izmenjave mladih (Itzel, 2008), kasneje leta 1996 pa je Evropska komisija predlagala akcijski program EU: Evropska prostovoljna služba za mlade. V letu 2000 sta se oba programa združila v akcijski program Mladina (2000-2006) (European Commission, 2007), ki je bil dopolnjen z dodatnimi ukrepi, kot je projekt Pobude za mlade, namenjen inovativnim in ustvarjalnim projektom, s katerimi se spodbuja socialno vključevanje mladih. Program Mladina je bil novembra 2006 z odločbo 1714/2006/ES nadgrajen v program Mladi v akciji (2007-2013), ki ga različni raziskovalni zaključki navajajo kot vodilen instrument na področju mladinskega dela in mladinske politike tako na ravni EU, kot tudi na nižjih političnih ravneh (Itzel, 2008; European Commission, 2011; Ferjančič, 2011; Kustec Lipicer \& Deželan, 2010). 
Odgovornosti in pristojnosti za izvajanje mladinske politike so torej še vedno v rokah posamezne države članice EU, ob hkrati dokaj aktivnih spodbudah, ki jih v obliki priporočil in z razpisovanjem programov za razvijanje sodelovanja ter mobilnosti mladih na (sub) nacionalnih ravneh, kot je to primer analiziranega programa MvA, pripravlja Evropska komisija. Kot pomemben upravljavski mehanizem pa se sicer nasploh na področju mladinske politike na ravni EU uporablja odprta metoda koordinacije ${ }^{2}$ (glej tudi Laine \& Gretschel, 2009, str. 192; Fink Hafner, 2010; Lajh \& Štremfel 2012).

\section{Teoretsko problemski kontekst programa Mladi v akciji}

Gledano s teoretskega zornega kota javnih politik in upravljanja (Hogwood \& Gunn, 1984; Fink Hafner, 2007) je na ravni EU mladinska politika, kot opredeljena v pravkar izpostavljenih temeljnih dokumentih in smernicah, razumljena kot t. i. medsektorska politika. Izvajanje politike je usmerjeno v različne ciljne skupine mladih. Skozi čas so bili s temi nameni v okviru Evropske komisije vzpostavljeni že omenjeni programi za mlade, ki jih je mogoče glede na njihove funkcije in namen razumeti kot posebno vrsto spodbujevalnih, finančno-operativnih in informacijskih javnopolitičnih ukrepov (Majchrzak, 1984; Holwett \& Ramesh, 1995), s katerimi želi EU doseči temeljni cilj poseganja na področje problematik mladih, to je spodbude različnih skupin mladih k aktivnejšemu sodelovanju in participaciji v družbi. S takim pristopom k razumevanju in vstopanju v javno politiko mladih se je EU z uvedbo programa MvA mnogo aktivneje vpletla v dejansko izvajanje mladinske politike tako v okviru EU kot tudi na politično nižjih ravneh.

V praksi to pomeni, da Evropska komisija v imenu EU razpiše program, ki ga na nacionalni in subnacionalnih ravneh izvajajo mladinske organizacije na omenjenih dveh ravneh. Mladinske organizacije tako pri izvajanju projektov, ki jih prijavljajo v okviru programa MvA, postanejo ključni udeleženci programa oz. s tem izvajalci javnopolitičnega instrumenta, ki spodbuja participacijo mladih v EU in v lokalnem okolju posameznih držav članic (Williamson, 2002, str. 46). Na nekakšen način omenjene organizacije v imenu in za EU v praksi prevzemajo in izvajajo ključno vlogo pri zagotavljanju mladinske politike z vidika svetovanja za konstruktiven razvoj, tako da prispevajo k partnerstvu storitev za mlade.

Z upravljavskega vidika Evropska komisija na nacionalni ravni izbere koordinatorja, ki skrbi za razpis in nazor nad izvedbo programa na nacionalni ravni. To funkcijo v Sloveniji izvaja Zavod Movit na mladina. Vloga nacionalnih

2 Odprto metodo koordinacije na področju mladine je kot ustrezno obliko sodelovanja predlagala Evropska komisija s sprejemom Bele knjige: Nova spodbuda za evropsko mladino (White Paper, 2001). Gre za vzpostavitev sodelovanja med državami in med različnimi igralci znotraj držav, vendar to ne pomeni pogodbene vzpostavitve sodelovanja znotraj EU (Fink Hafner, Lajh \& Deželan, 2010, str. 28). Temelji predvsem na skupnem ugotavljanju in določanju ciljev, ki bi jih naj dosegli (sprejema Svet EU); skupnem določanju merilnih instrumentov (statistika, kazalniki, smernice); ter na primerjalnih analizah, primerjavi zmogljivosti držav članic in izmenjavi najboljših praks (nadzoruje Evropska komisija) (Europa, 2012). 
državnih institucij, pristojnih za izvajanje politike v državi, je pri opisanem programu mladinske politike EU omejena na nadzorno funkcijo izvajanja dela nacionalnih koordinatorjev. V slovenskem primeru je to Urad RS za mladino (v nadaljevanju URSM), ki je organ v sestavi Ministrstva za znanost, izobraževanje, kulturo in šport ${ }^{3}$, katerega siceršnja naloga na nacionalni ravni je izvajanje ukrepov, s katerimi spodbuja in razvija organiziranost mladih v državi. Glavni namen sodelovanja URSM z drugimi mladinskimi organizacijami v Sloveniji je izboljšati položaj mladih ter povečati njihov vpliv v družbi.

Z upravljavskega in hkrati tudi javnopolitično širšega vidika v opisanem programu MvA lahko prepoznamo ideje t. i. večnivojskosti in večnivojskega vladanja ter upravljanja (angl. multilevel governance). Ta se nanaša na razmerja med političnimi igralci - javnimi in zasebnimi, ki so medsebojno bolj ali manj intenzivno povezani in z zasledovanjem istega cilja delujejo na različnih ravneh delovanja, od subnacionalne, nacionalne, do nadnacionalne. Večinoma je ta koncept prepoznan kot pozitiven pristop k deliberativnemu oblikovanju in izvajanju javnih politik, v katerega imajo demokratično možnost vključitve vsi javni in zasebni igralci na različnih ravneh političnega odločanja (Marks, 1996; Marks \& Hooghe, 1997; Citi \& Rhodes, 2007). Kot se pokaže skozi čas in izkušnje v vsakodnevnih javnopolitičnih in upravljavskih procesih, pa lahko prihaja od opisanega teoretskega ideala tudi do velikih odstopanj. $V$ tem kontekstu npr. Piattoni (2009) predpostavlja in nadalje preverja, ali v primeru zagotavljanja načel večnivojskega upravljanja med javnimi in zasebnimi igralci, kot tudi med subnacionalnimi, državnimi in nadržavnimi oz. med domačimi in mednarodnimi igralci prihaja do načrtnega zamegljevanja njihovih formalnih pristojnosti, kar naj bi igralcem prinašalo večje koristi in lažje zadovoljevanje njihovih interesov. Piattoni (prav tam) predpostavlja, da se lahko v opisanih razmerah tovrstni odnosi utrjujejo in postajajo močnejši, povečuje se njihova stopnja legitimnosti v javnosti, ki se jo utemeljuje na novem, «všečnem« diskurzu in prikazovanju dejstev, ki jih ni mogoče preveriti oz. ki se na koncu zožijo zgolj na zadovoljevanje normativnega izpolnjevanja pogojev za sodelovanje.

Ključna težava mladinske politike na nacionalni ravni v Sloveniji je splošno pomanjkanje sistemske ureditve. Do nedavnega je bila ključni in edini dokument na področju mladinske politike na nacionalni ravni Strategija URSM na področju mladinske politike do leta 2010 (URSM, 2012), ki pa ni imela ustrezne zakonske podlage in zato ni nikoli dejansko zaživela. Po dolgih letih razpravljanja je bil leta 2010 sprejet Zakon o javnem interesu v mladinskem sektorju (ZJIMS, 2010) kot krovni zakon na mladinskem področju, ki med drugim opredeljuje tudi mladinsko delo, kamor spada tudi izvajanje projektov v okviru programa MvA EU.

3 URSM, kotorgan v sestavi Ministrstva za znanost, izobraževanje, kulturo in šport opravlja naloge in izvaja ukrepe, s katerimi spodbuja in razvija organiziranost mladih, njihovo participacijo v družbenih procesih, neformalno izobraževanje mladih, informiranje in svetovanje za mlade, mobilnost in mednarodno sodelovanje mladih. Urad spremlja aktivnosti mladinskih in drugih organizacij, evalvira njihovo delo, izobražuje in usposablja izvajalce dejavnosti za mladinsko delo na nacionalni in lokalni ravni (Urad RS za mladino, 2011a). 
Ko se odločimo za preučevanje vplivov izvajanja programa MvA, se moramo torej izhodiščno osredotočiti na tiste vsebine ciljev programa, ki jih je postavil sofinancer razpisanih programov, kljub temu da na nacionalni ravni svoje cilje in načela za razvoj in delovanje mladinskega sektorja neodvisno od tega postavlja tudi nacionalni organ mladinske politike, URSM. Za izpolnjevanje ciljev in načel osrednja organa na obeh političnih nivojih uvajata mehanizme, s pomočjo katerih se zasledujejo njuni cilji. Cilje Evropske komisije, kot so opredeljeni v analiziranem programu MvA, je mogoče prepoznati v petih akcijah, na katere mladinske organizacije z nacionalnih in subnacionalnih ravni, v slovenskem primeru torej lokalnih, prijavljajo svoje projekte (Movit na mladina, 2009; Cugmas, 2011).

Nadaljnja analiza ciljev mladinske politike, kot jo opredeljujejo samostojno posamezne od preučevanih ravni (European Commission, 2010; URSM, 2011; Murn, 2010) pokaže, da vsaka raven poudarja svoje vsebinske cilje, na vseh pa je mogoče prepoznati cilje kot so participacija mladih, vključevanje in motivacija mladine z manj priložnostmi in aktivno državljanstvo. Glede na nakazane vsebinske podobnosti in specifiko področja mladine in načel mladinske politike - vlogo mladih in mladinskih organizacij ter reprezentativnih struktur na nacionalni in evropski ravni - bi sicer bilo zelo pomembno, da bi se sprejeti cilji med posameznimi ravnimi tudi upravljavsko operativno dopolnjevali, do česar pa po primerjavi vsebin operativnih ciljev neposredno ne prihaja. Organi na različnih ravneh postavljajo različne cilje, kar pomeni da z izvajanjem programa MvA vsebinskega dopolnjevanja ciljev in tako tudi medsebojne prepletenosti njihovega izpolnjevanja neposredno ne gre pričakovati.

\section{Izkušnja izvajanja programa Mladi v akciji v podravski regiji}

Po pregledu vseh projektov in razvrščanju v posamezne sklope akcij lahko vidimo, da se je v podravski regiji v Sloveniji največ projektov izvajalo v okviru podakcij 1.1 in 1.2 in akcije 2., ki se vsebinsko nanašajo na spodbujanje evropskega sodelovanja in aktivnega državljanstva mladih ter evropskega državljanstva in evropske prostovoljne službe (Cugmas, 2011). Z vidika ciljev EU to odraža pomemben premik k razvoju solidarnosti in spodbujanju strpnosti med mladimi, predvsem z namenom krepitve socialne kohezije znotraj EU. Po drugi strani je bilo najmanj izvedenih projektov v podakcijah 1.3, 3.1 in 5.1 (Cugmas, 2011) oz. neuresničevanje ciljev mladinske politike EU, ki se nanašajo na medsebojno razumevanje mladih iz različnih držav, prispevanje k razvoju kakovosti sistemov podpore za aktivnosti mladih ter zmogljivosti organizacij civilne družbe na področju mladine.

Z upravljavsko operativnega vidika se kaže, da število projektov, ki jih prijavljajo podravske mladinske organizacije z leti narašča, čeprav je v celotni slovenski strukturi odstotek prijavljenih projektov relativno nizek glede 
na število mladih v tej regiji. ${ }^{4}$ Od leta 2008 do 2010 je bilo v regiji prijavljenih za več kot 35 \% več projektov. Vendar pa obratno sorazmerno s to številko delež sprejetih projektov pada, iz 50,4 \% na 43,6 \% v letu 2010.

Tabela 1: Primerjava med številom prijavljenih in sprejetih projektov v obdobju 2008-2010 v celotni Sloveniji in v podravski regiji

\begin{tabular}{|l|c|c|c|c|}
\hline \multirow{2}{*}{ Akcija } & \multicolumn{2}{|c|}{ Skupaj } & \multicolumn{2}{c|}{ Skupaj } \\
\cline { 2 - 5 } & $\begin{array}{c}\text { Število vseh } \\
\text { predloženih } \\
\text { projektov v } \\
\text { Sloveniji }\end{array}$ & $\begin{array}{c}\text { Število } \\
\text { predloženih } \\
\text { projektov v } \\
\text { podravski regiji } \\
(\%)\end{array}$ & $\begin{array}{c}\text { Število vseh } \\
\text { sprejetih } \\
\text { projektov v } \\
\text { Sloveniji }\end{array}$ & $\begin{array}{c}\text { Število vseh } \\
\text { sprejetih } \\
\text { projektov v } \\
\text { podravski regiji } \\
(\%)\end{array}$ \\
\hline podakcija 1.1 & 174 & 22 & $86(24,9)$ & $12(33,3)$ \\
\hline podakcija 1.2 & 274 & 25 & $70(20,3)$ & $10(27,8)$ \\
\hline podakcija 1.3 & 16 & 2 & $9(2,6)$ & $0(0)$ \\
\hline akcija 2 & 167 & 11 & $122(35,4)$ & $10(27,8)$ \\
\hline podakcija 3.1 & 85 & 12 & $27(7,8)$ & $2(5,6)$ \\
\hline podakcija 4.3 & 51 & 5 & $25(7,2)$ & $2(5,6)$ \\
\hline podakcija 5.1 & 12 & 1 & $6(1,7)$ & $1(2,8)$ \\
\hline Skupaj & 737 & $78(10,6)$ & $345(46,8)$ & $37(47,4)$ \\
\hline
\end{tabular}

Vir: lastni

V obdobju 2008 do 2010 je bilo v okviru izvajanja programa MvA v Sloveniji skupaj prijavljenih 737 projektov, od tega 78 oz. 10,6 \% v podravski regiji. Na ravni cele države je bilo v povprečju končno sprejetih 46,8 \% vseh prijavljenih projektov in $47,1 \%$ v podravski regiji. Tako na ravni države kot tudi na ravni preučevane regije je posameznim akcijam namenjena podobna pozornost (glej tabelo 1).

$\checkmark$ nadaljevanju bomo pobliže pogledali še izvedbo ustreznega razporejanja finančnih sredstev. Sedemletni proračun programa MvA (2007-2013) znaša 885 milijonov evrov. O letnih proračunih odločata Evropski parlament in Svet EU (Evropska komisija, 2008). Vsaka akcija in podakcija ima vnaprej dodeljena finančna sredstva, ki se razdelijo glede na vsebinske prioritete, ki jih postavi Evropska komisija. V letu 2008 je bilo v Sloveniji skupaj podeljenih 87 \% razpoložljivih sredstev, v letu 2009 97,27 \% sredstev, v letu 2010 pa se je dodelilo 98,54\% razpoložljivih sredstev, kar je največ v analiziranih letih (Movit na mladina, 2010). Od omenjenih zneskov se je podravski regiji v letu 2008 odobrilo $6 \%$ sredstev, v letu $200916 \%$, v letu 2010 pa je delež padel na $10,49 \%$, kar pomeni iz 204.339,00 € na 154.794,00 €, pri čemer sta bila v letu 2009 v podravski regiji prijavljena dva večja vsebinska projekta, ki sta dobila večino finančnih sredstev namenjenih podravski regiji, v letu 2010 pa je bil takšen en projekt (Mladi v akciji, 2010).

4 Na program MvA se v Sloveniji prijavljajo mladinske organizacije iz desetih regij. Največ prijav je iz osrednjeslovenske regije, nato savinjske, tretja glede na oddane prijave je podravska regija (Mladi v akciji, 2010). 


\section{Grafikon 1: Višina sredstev, namenjenih posamezni akciji v podravski regiji v obdobju 2008-2010}

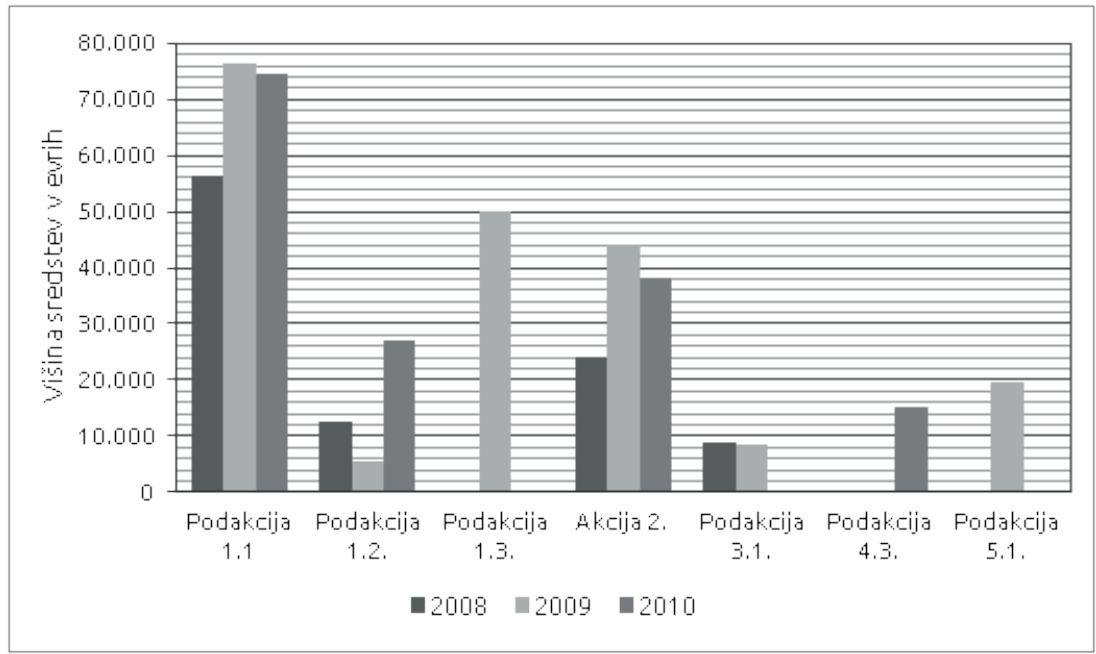

Vir: Movit na mladina $(2009,2010)$

Največ sredstev je bilo v Sloveniji dodeljenih podakciji 1.1 - Mladinske izmenjave, enako velja tudi za podravsko regijo, v tej podakciji je bilo tudi največ izvedenih projektov (glej grafikon 1). Najmanj sredstev pa je bilo namenjenih za usposabljanje in povezovanje v mrežo tistih, ki so aktivni v mladinskem delu in mladinskih organizacijah, torej podakciji 4.3.

Končno je za nas relevanten tudi vpliv izvedbe projektov, torej kakšne učinke imajo cilji, ki smo jih opredelili kot izpolnjene z izvedbo projektov. Kustec Lipicer \& Deželan (2010) sta učinke ciljev, ki jih postavlja Evropska komisija, identificirala na treh ravneh: vsebinski; vodstveno-operativni in sociodemografski. Merjenje učinkov ciljev je izjemno težko, zato je za nas relevantno predvsem vsebinsko vrednotenje učinkov ciljev, saj nas zanima, v kolikšni meri, na koga in kakšen vpliv imajo posamezni izvedeni projekti. $\vee$ primeru preučevane regije se pokaže, da se na normativni ravni z izvedbo projektov izpolnjuje večina ciljev, ki jih poudarja Evropska komisija. Učinek teh ciljev, ki bi se neposredno odražali na različnih vpletenih ciljnih skupinah, pa je mnogo težje izmeriti. Še najbližje temu je merjenje učinkov na samih mladih. V primeru obravnavane podravske regije bi glede na dejstvo, da organizacije prijavljajo vedno več projektov, pričakovali pozitiven učinek izvajanja programa MvA, vendar pa podatki hkrati tudi pokažejo, da je število sodelujočih v projektih manjše. Vzrok temu lahko iščemo v naravi projektov, torej primarno vsebini in ciljih EU, ki morajo biti izpolnjeni, a se hkrati vsebinsko ne skladajo z dejanskimi potrebami ter zmožnostmi mladinskih organizacij na lokalni ravni, nadalje pa tudi v finančno-operativnih omejitvah. Večina organizacij v regiji namreč zaradi svoje majhnosti nima zadostnega lastnega vložka za sodelovanje pri projektih, 
ali pa lahko preživi zgolj za čas trajanja projekta (več o tem glej na primeru slovenske izkušnje npr. tudi v Kustec Lipicer \& Deželan, 2010). ${ }^{5}$

Prav tako je podajanje celovite vsebinske ocene učinkov doseženih ciljev v primeru analiziranega programa problematično zaradi vsebinske ohlapnosti in (ne)izmerljivosti ciljev programa bodisi na nadnacionalni, nacionalni, ali lokalni ravni. Objektivno merjenje sprememb v odnosu do evropskega državljanstva, aktivnega državljanstva, razvoja solidarnosti in spodbujanja strpnosti ter krepitev medsebojnega razumevanja je praktično nedosegljivo in neizvedljivo, zato je mogoče o njem sklepati zgolj posredno preko pridobivanja subjektivnih ocen, zaznav in mnenj o odnosu in vedenjskih spremembah vpletenih ter morebitnih normativnih spremembah in redefiniciji javnopolitičnih ciljev v primeru odločevalskih struktur. Nesporno pa je na sedanji točki mogoče zatrditi, da sodelovanje v programu MvA za mladinske organizacije pomeni večjo aktivnost tako organizacij samih, kot tudi posameznikov.

\section{Zaključek}

Program Mladi v akciji je program mladinske politike na ravni EU, s katerim le-ta ozko formalno gledano zasleduje zgolj lastne cilje, in za izvajanje katerega se lahko prijavijo tisti nacionalni in subnacionalni igralci, ki jih tovrstno zastavljene vsebine zanimajo. Vendar pa praksa, ki jo potrjuje tudi v tem članku izvedena analiza, kaže, da program MvA EU tako vladni igralci na različnih političnih ravneh, mladinske organizacije, kot tudi strokovna javnost pojmujejo kot bistven in nepogrešljiv element na področju mladinske politike in mladinskega dela na različnih, ne zgolj na politični ravni EU. Program je skozi leta postajal vedno bolj priljubljen tako med vladnimi igralci kot tudi med mladimi, kar potrjujejo številski podatki, iz katerih je razvidno, da se za njegove namene pripravlja vedno več projektnih predlogov in da se zaradi naraščajoče konkurence s tem povečuje tudi kakovost teh predlogov. Nadalje se je v analiziram primeru podravske regije pokazalo, da program v njej izvaja t. i. eksistencialno operativno-finančno funkcijo, saj mnogo mednarodnih mladinskih aktivnosti na področju mladinskega sektorja na lokalni ravni brez finančne podpore EU za realizacijo projektov, ne bi bilo nikoli izvedenih. V vsebinskem smislu se vpliv programa EU kaže predvsem v povečani mobilnosti mladih, v pridobitvi izkušenj, spoznavanju novih kultur in vključevanju v družbo, nenazadnje tudi v pridobivanju kompetenc za kasnejšo zaposlitev. Tudi mladinske organizacije pozitivno ocenjujejo program (več v Kustec Lipicer \& Deželan, 2010). Z upravljavskega vidika pa se vpliv kaže v krepitvi elementov vodenja, menedžiranja, projektnega menedžmenta v javnih politikah in tudi med posameznimi skupinami igralcev, ki jo oblikujejo in izvajajo (prav tam).

5 Gre za koncept t.i. "muh enodnevnic«, torej organizacij, ki se na sceni lokalnih mladinskih organizacij obdržijo povprečno kratek čas, saj se njihovo delovanje ukine zaradi nezainteresiranosti mladih in pomanjkanja sredstev in so zato uspešne le pri prijavi projektov. Več kot enkrat je projekt prijavilo le 10 organizacij, kar predstavlja le tretjino vseh organizacij v tej regiji (Mladi v akciji, 2010). 
Kljub pozitivnim izsledkom, ki jih za sabo pušča izvajanje programa MvA nasploh, pa je za njegovo delovanje v začrtani smeri izjemnega pomena, na kakšen način se oblikujejo ustrezna upravljavska razmerja med igralci, vpletenimi izvedbo programa. Tako je mogoče opaziti, da je zlasti strateški in dolgoročnejši medsebojni dialog med igralci navkljub vsebinski sorodnosti ciljev na različnih političnih ravneh neprepoznaven in osnovan pretežno na izvrševanju formalnih pristojnosti. EU z omenjenim programom sicer skrbi za zasledovanje lastnih ciljev, ki pa so hkrati z izjemo bolj evroskeptičnih držav članic, sorodni vsebinskim ciljem tudi na nižjih političnih ravneh. V našem primeru se je tudi pokazalo, da izvajanje programa MvA, ki ga podpira EU, ni ozko osredotočeno zgolj na zasledovanje evropskih ciljev, ampak pogosto zagotavlja preživetje posameznih mladinskih organizacij in s tem posredno tudi nadaljevanje zastavljene mladinske politike in dela tako na nacionalni kot na lokalnih ravneh, in ima zato pomemben posreden učinek tudi na javnopolitične procese na omenjenih ravneh.

Koncept večnivojskosti kot $v$ začetku teoretsko opredeljen, se torej v analizirani izkušnji izvajanja programa MvA dejansko izvaja v neke vrste svojstveno prilagojeni obliki, čeprav v njegovem konceptu ideja večnivojskosti formalno sploh ni predvidena. EU kot finančna podpornica s programom MvA namreč narekuje dinamiko izvajanja lastne politike, pri čemer za izvedbo programa politično nižje ravni nudijo zgolj svojo administrativno pomoč. Hkrati pa omenjene nacionalne in subnacionalne ravni na račun te finančne podpre, ki jo dobijo izvajalci projektov, in hkratne ohlapnosti ciljev programa MvA, lahko razvijajo svojo lastno politiko na polju mladih, ki vsebinsko sploh ni nujno skladna s pričakovanji, cilji in upravljanjem mladinske politike EU.

Mateja Cugmas je leta 2011 diplomirala na Fakulteti za družbene vede Univerze v Ljubljani, na študijski smeri Politologija - analiza politik in javna uprava. Šolanje nadaljuje na Fakulteti za družbene vede, smer Politologija - svetovne študije. Za diplomsko delo je skupaj z mentorico izr. prof. dr. Simono Kustec Lipicer prejela priznanje Mladinskega sveta Slovenije.

Dr. Simona Kustec Lipicer je izredna profesorica za področje analize politik, kot visokošolska učiteljica je zaposlena na Fakulteti za družbene vede Univerze v Ljubljani in kot raziskovalka na Centru za politološke raziskave iste institucije. Pedagoško sodeluje v okviru policy analitičnih predmetov na domači fakulteti, Fakulteti za upravo Univerze v Ljubljani in Fakulteti za politične znanosti Univerzev Zagrebu. Raziskovalno sodeluje vokviru več domačih in mednarodnih raziskovalnih projektov s področij volilnega vedenja, analize politik in športne politike. Je (so) avtorica znanstvenih monografij, številnih domačih in mednarodnih strokovnoznanstvenih člankov, prejemnica štipendij EU. 
Vrednotenje vplivov EU na področju mladinske politike na subnacionalni in nacionalni ravni: primer programa Mladi v akciji v Sloveniji

\section{Literatura in viri}

- Cepin, M. (2009). Mladinsko delo kot instrument mladinskih politik. Pridobljeno 20.8. 2012, s http://www.mladinski-delavec.si/datoteke/mdnfi/images/03-02. pdf

- Citi, M. \& Rhodes, M. (2007). New Modes of Governance in the EU: Common Objectives versus National Preferences. European Governance Papers (EUROGOV), No. N-07-01. Pridobljeno 18. 5. 2012, s http://eucenter.wisc.edu/ OMC/New\%200MC\%20links/egp-newgov-N-07-01.pdf

- Cugmas, M. (2011). Vrednotenje evropskega sodelovanja na področju mladinske politike v Sloveniji. Diplomsko delo. Ljubljana: Fakulteta za družbene vede.

- Europa (2011). White Paper on Youth. Pridobljeno 21. 6. 2012, s http://europa. eu/legislation_summaries/education_training_youth/youth/c11055_en.htm.

- Europa (2012). Open Method of Coordination. Pridobljeno 23. 7. 2012, s http://europa.eu/legislation_summaries/glossary/open_method_ coordination_en.htm

- European Commission (2007). Youth Programme. Pridobljeno 3. 7. 2012, s http://ec.europa.eu/youth/archive/program/index_en.html.

- European Commission (2010). Youth in Action Programme. Pridobljeno 13. 6. 2012, s http://ec.europa.eu/youth/youth-in-action-programme/doc74_ en.htm

- European Commission (2011). Commission report to the European Parliament, the Council, the European Economic and Social Committee and the Committee of the Regions. Interim evaluation of the 'Youth in Action' Programme. Pridobljeno 20. 7. 2012, s http://eurlex.europa.eu/LexUriServ/LexUriServ. do?uri=COM:2011:0220:FIN:EN:PDF

- European Commission (2012). Legal Basis. Pridobljeno 21. 6. 2012, s http:// ec.europa.eu/youth/policy/legal-basis_en.htm

- European Union (2012). Education, Training, Youth. Pridobljeno 3. 7. 2012, s http://europa.eu/pol/educ/index_en.htm

- Evropska komisija (2008). Vodnik po programu Mladi v akciji 2008. Pridobljeno 20. 7. 2011, s http://ec.europa.eu/youth/pdf/doc599_sl.pdf

- Ferjančič, P. (2011). Intervju z avtorico, Ljubljana, 20. julij 2011.

- Fink Hafner, D. (2007). Uvod v analizo politik. Ljubljana: Fakulteta za družbene vede.

- Fink Hafner, D. (ur.) (2010). The Open Method of Coordination. Ljubljana: Fakulteta za družbene vede.

- Fink Hafner, D., Lajh, D. \& Deželan, T. (2010). The Open Method of Cooperation in the Global Context of Policy Cooperation. V Fink Hafner, D. (ur.). The Open Method of Coordination (17-35). Ljubljana: Fakulteta za družbene vede.

- Hogwood, W. B. \& Gunn, A. L. (1984). Policy Analysis for the Real World. New York: Oxford University Press.

- Howlett, M. \& Ramesh, M. (1995). Studying Public Policy: Policy Cycles and Policy Subsystems. Toronto: Oxford University Press.

- Itzel, C. (2008). Youth. Pridobljeno 25. 6. 2012, s http://circa.europa.eu/irc/ opoce/fact_sheets/info/data/policies/culture/article_7316_en.htm

- Kuhar, M. \& Leskošek, V. (2008). Mladinsko delo na lokalni ravni: primerjalna analiza petih držav. Socialna pedagogika 12(4), 325-345. 
- Kustec Lipicer, S. \& Deželan, T. (2010). "Youth in Action 2007-2013" Programme in Slovenia - Interim evaluation 2007 - 2009. Ljubljana: Fakulteta za družbene vede.

- Kustec Lipicer, S. \& Deželan, T. (2010a). "Youth in Action 2007-2013" Programme in Slovenia - Interim evaluation 2007 - 2009. Annex - tables, graphs, source and references. Ljubljana: Fakulteta za družbene vede.

- Laine, S. \& Gretschel, A. (2009). Whose arena is the EU youth policy? Young participants' involvement and influence in the EU youth policy from their own points of view: Case of the EU presidency Youth Event in Hyvinkää, Finland. YOUNG Nordic Journal of Youth Research 17(2), 191-215.

- Lajh, D. \& Štremfelj, U. (2011). Exploiting the Potential of the Open Method of Coordination in Slovenian Education Policy. Czech Sociological Review 47(3), 507-530.

- Majchrzak, A. (1984). Methods for Policy Research. Newbury Park, London, New Delhi: Sage.

- Marks, G. \& Hooghe, L. (1997). The Making of a Polity: The Struggle over European Integration. European Integration online Papers 1(4).

- Marks, G. (1996). An Actor-Centred Approach to Multi-Level Governance. Regional and Federal Studies 6(2), 20-40.

- Marks, G. (1996). Exploring and Explaining Variation in Cohesion Policy. Pridobljeno 6. 5. 2011, s http://www.unc.edu/ gwmarks/assets/doc/ marks\%20-\%20 exploring\%20and\%20explaining\%20variation\%20in\%20 EU\%20cohesion\%20policy.pdf

- Mladi v akciji (2010). Sprejeti projekti. Pridobljeno 5. 6. 2012, s http://www. mva.si/mladi-v-akciji/sprejeti-projekti/

- Movit na mladina (2009). Odtisi mladih: program Mladi v akciji v letu 2008. Ljubljana: Zavod Movit.

- Movit na mladina (2010). Odtisi mladih: program Mladiv akciji v letu 2009. Ljubljana: Zavod Movit.

- Murn, K. (2010). Mladinsko delo in mladinska politika na lokalni ravni. Ljubljana: Ministrstvo za šolstvo in šport, Urad Republike Slovenije za mladino.

- Negueira, A. M. (2012). Mladinska politika. Pridobljeno 3. 7. 2012, s http://www.europarl.europa.eu/ftu/pdf/sl/FTU_4.17.2.pdf.

- Piattoni, S. (2009). Multi-level Governance in the EU. Does it Work? Globalization and Politics - A Conference in Honour of Suzane Berger, MIT, 8-9 May 2009. Pridobljeno 18. 5. 2012, s http://www.princeton.edu/ smeunier/ Piattoni.

- The Treaty on the Functioning of the European Union (2008). Pridobljeno 18. 5. 2012, s http://eur-lex.europa.eu/LexUriServ/LexUriServ.do?uri=OJ:C:200 8:115:0047:0199:en:PDF

- Urad RS za mladino (2011). Programi za mlade. Pridobljeno 20. 7. 2012, s http://www.ursm.gov.si/si/delovna_podrocja/programi_za_mlade/

- Urad RS za mladino (2012). Zakonodaja in dokumenti. Pridobljeno 3. 7. 2012, s http://www.ursm.gov.si/si/zakonodaja in dokumenti/

- White Paper: a new Impetus for European Youth (2001). Pridobljeno 3. 7. 2012, s http://eurlex.europa.eu/LexUriServ/LexUriServ. do?uri=COM:2001:0681:FIN:EN:PDF

- Williamson, H. (2002). Supporting young people in Europe: Principles, policy and practice. Strasbourg: Council of Europe Publishing. Pridobljeno 23. 7. 2011, shttp://www.coe.int/t/dg4/youth/Source/Resources/ Publications/Supporting_young_people_en.pdf

- Zakon o javnem interesu v mladinskem sektorju (ZJIMS). Ur.l. RS, št. 42/2010. 
SUMMARY

\section{EVALUATION OF THE IMPACT OF EU ON THE FIELD OF YOUTH POLICY AT SUBNATIONAL AND NATIONAL LEVEL: EXAMPLE OF THE YOUTH IN ACTION PROGRAMME IN SLOVENIA}

Keywords: multi-level policy, evaluation, youth policy, program Youth in Action, Podravje

In the article the main emphasis is given on the evaluation analysis of Slovenian experience with the implementation and management of EU program Youth in Action 2007-2013 and to the impacts that it brings to the different political levels at which it operates - subnational, national and transnational, and to different groups of young people, as direct users of this program. The program has been designed in order to increase the commitment of young people and the strengthening of key competences for lifelong learning, known as increasing the employability and inclusion of young people into the society. The guiding principle of youth policy is based on promoting and offering positive tangible and intangible transfers that contribute to the improvement and development of young people's lives and to their generally higher participation in society. Youth policy is an integrative, cross-sectoral policy, with the aim of promoting cooperation between young people, taking into account the total volume of social, cultural and political issues that affect them. In the above context the concept of youth work as a form of working with young people on voluntary basis takes one of the crucial roles. In the youth field this focus is of strong public interest and is closely related to the Youth in Action Programme, which is also the subject of the analysis in this article.

The aim of our analysis is to evaluate how the results achieved in the implementation of the program at the subnational level meet the multilevel policy idea on one hand and young people as direct target group of the program on the other. With this regard the analysis of the program in terms of evaluating its goals, objectives and management aspects is being conducted. A concrete case study of Podravje region, designated as least developed in the field of youth policy in Slovenia is analysed.

Theoretical foundations for the analysis are based on the theories of public policy, governance and especially the principles of multi-level governance. Within the evaluation study of the impacts of the program Youth in Action it is necessary to focus on the content of the program objectives which were set by the EU as the co-financier of the program, despite the fact that at the (sub)national levels objectives and principles for the development and operation of the youth sector are independently imposed by (sub)national authorities in the field of youth policy. To fulfill the objectives and principles 
the central authority at each political level introduce mechanisms through which to pursue their goals. The objectives of the European Commission, as defined in the analysed program Youth in Action, can be identified in five actions on which youth organizations, from national and subnational level, are applying their projects. According to the substantive similarities and specifics of youth area and youth policy principles - role of youth and youth organizations and representative structures at the national and EU level - we should expect that adopted goals of each individual political level would complemented in managing and operation, but by the comparison of the content of operational objectives this has not been directly confirmed. Authorities at various levels set different goals, so that with the implementation of the Youth in Action program there are no substantive complementarities of goals and also the interlink of their compliance cannot be directly expected.

Research findings in the case of Slovenian case study Podravje region, considered as one of the least developed in terms of youth policy principles in Slovenia show that the effects of the objectives of the Youth in Action on young people in a region have been clear and successful. After reviewing all the projects and classification in the various parts of actions, we can see that in the Podravje region in Slovenia most projects were carried out in the framework of 1.1 and 1.2 as well as also 2 . subaction, which are essentially concentrated on the promotion of European cooperation, active citizenship of young people, European citizenship and European voluntary Service. The managerial point of view shows that the number of projects registered by youth organizations in Podravje increases in time, although the percentage of projects in the entire Slovenian structure is relatively low in relation to the number of young people in the region. More than 35\% more projects were reported as submitted from 2008 to 2010 in the region. However, conversely proportional to this, the percentage of accepted projects dropped from $50.4 \%$ to $43.6 \%$ in 2010 . All together 737 projects were implemented in the frameworks of Youth in Action program in Slovenia in the period between 2008-2010, from this 78 or $10.6 \%$ in the analysed region. At the level of entire country on average $46.8 \%$ of all registered projects and $47.1 \%$ in Podravje region were finally accepted. Both, at the state level as well as at studied region level, similar attention to each action was dedicated. In 2008, in Slovenia $87 \%$ of the available funds were conferred, in 2009 97.27\% founds, in 2010 $98.54 \%$ of the available resources were conferred, which is the highest share in the analysed years (Movit on Youth, 2010). In the case of Podravje region $6 \%$ of the above mentioned funds were approved in 2008, in $200916 \%$, in 2010 the share dropped again to $10.49 \%$, which means from $204,339.00 €$ to $154,794.00 €$, but with the observation that in 2009 two major substantive projects in the region were reported positive, receiving most of the funding, and in 2010 one such project was reported to be financed. Most of the funds in Slovenia were allocated to the sub-action 1.1 - Youth Exchanges, the same applies for Podravje region, in this sub-action was also taken up the most of projects. For the training and networking of those who were active in youth 
work and youth organizations, so in the sub-action 4.3 at least funds were earmarked. Finally, the impacts of the implemented projects are also relevant for us to be aware of, knowing the effects of the goals that were in advance defined to be set with the implementation of the projects. Measuring this kind of impact is extremely difficult, since we need to be interested in how much, to whom and what impacts have been made by or because of the implementation of the individual project. In a way the question of knowing substantive project as well as also program and indirectly youth policy goals performance is at stake. In the case of the studied region it was shown that at the normative level project implementation meets most of the objectives highlighted by the European Commission which are at the same time also close to the policy goals as defined at the national level. The effect of these goals, which would directly reflect at the different involved groups is much more difficult to tackle. The closest to these is to measure the effects on the young people themselves. In the case of Podravje region, despite the fact that organizations have been applying more and more projects, we would expect positive impact of the implementation of Youth in Action program, but at the same time the data also show that the number of participants in projects is decreasing. The reason for this can be found in the nature of the projects, so primarily in the content and objectives of the EU, which must be met, and which at the same time substantively does not match with the actual needs and capacities of youth organizations at the local level. Also the financial and operational constraints at the local level are evident frequently. Most organizations in the region do not have sufficient background of financial and human resources for the application and later implementation of the project due to their small size.

The practice, which is also confirmed in the article, shows that governmental actors at different political levels, youth organizations, as well as expert community see the EU program Youth in Action as an essential and indispensable policy measure in the field of youth policy and youth work in various, not only at the EU political level arena. Over the years the program has become increasingly popular among government actors on both the national and subnational levels as well as among young people, which is confirmed by numerical data that report the increasing number of project proposals and also their quality. Furthermore, in the analysed case of Podravje region it has been shown that the Youth in Action program serves also in the operational and financial function for the region and even for the national policy, meaning that without the EU support the realization of projects would never be implemented in the youth sector. From the theoretical view it seems that the conclusions of the analysed case study reopen the debate of governing and managing the youth field from the multi-level perspective, which would fill the gap of the existing absence of more coherent, although in practice obviously present goals and principles of youth policy at various political levels. 